DOI: $10.2478 / \mathrm{v} \cdot 10169-010-0014-9$

\title{
FINITE ELEMENT ANALYSIS OF PLATE ON LAYERED TENSIONLESS FOUNDATION
}

\author{
R. BUCZKOWSKI ${ }^{1}$, W. TORBACKI ${ }^{1}$
}

\begin{abstract}
The method of calculations of a thick plate on the two-parameter layered foundation by the finite element method is presented. The numerical model allows to add a few (number of) foundation layers. The expressions for the element stiffness matrices of the foundation are based on 18-node zero-thickness interface elements. For modelling of thick plates the 9-node Mindlin element of the Lagrange family is used. The formulation of the problem takes into account the shear deformation of the plate and unilateral contact conditions between plate and foundation. The tensionless character of the foundation is achieved by removing from the global stiffness matrix the appropriate part of foundation stiffness attached to the node being in the separation stage. The advantages of the proposed algorithm are illustrated by numerical examples.
\end{abstract}

Key words: Mindlin plate element, layered two-parameter foundation, unilateral contitions.

\section{INTRODUCTION}

In analysis of plates resting on the elastic foundation using the Winkler model, a single parameter $k_{0}$ is used to describe beahaviour of the foundation. In that method, it is assumed that deflection at each point is proportional to the pressure applied at the point and completly independent from the pressures or deflections occuring at the neighbouring points along the foundation. A model of such medium can be represented by an infinite row of closely spaced elastic springs, each of them being deformed only by the pressure acting on it, without any shear deformations between them.

Filonenko-Borodich [1] and Pasternak [2] attempted to make the classical Winkler more realistic model postulating a two-parameter model. Their model takes into account the effect of shear interaction among adjacent points in the foundation. In this model the shear parameter has to be determined experimentally. Vlasov and Leont'ev [3] have introduced another arbitrary parameter, $\gamma$, dependent on soil material and thickness of the soil layer and suggested an approximate value of $\gamma$ between 1 and 2. However, they did not report the method of determining this parameter. In the work of Vallabhan and Daloglu [4], it has been shown how the soil parameter, $\gamma$, can be estimated using an

\footnotetext{
${ }^{1}$ Maritime University of Szczecin, Division of Computer Methods, Szczecin, Poland, e-mail: r.buczkowski@am.szczecin.pl
} 
iterative computational procedure for plates. The elastic foundation modulus $E_{s}$ was there a linear function throught the thickness of the foundation $z$

$$
E_{S}(z)=E_{1}+\left(E_{2}-E_{1}\right) \frac{z}{H}
$$

where $E_{1}=E_{s}(z=0)$ and $E_{2}=E_{s}(z=H)$ are the elasticity modulus at the top and bottom of the foundation, respectively. In the paper of Çelik and Omurtag [5] a quadratic variation of elasticity modulus $E_{s}$ was discussed, given as

$$
E_{s}(z)=E_{1}+\left(E_{2}-E_{1}\right) \frac{z^{2}}{H^{2}}
$$

Çelik and Saygun [6], Ozgan and Daloglu, Ozgan and Omurtag [7, 8], Buczkowski and Torbacki [9] have presented finite element technique where the material properties of the soil are taken into account to incorporate the surrounding effect. In the last paper the response of the foundation was modelled by using an 18-node quadratic interface elements of zero-thickness. The authors concluded that the lagrangian quadratic 9-node elements can be an optimal choice for modelling thick plates interacting with non-homogeneous foundation. The elastic plates of rectangular shape resting on a tensionless Winkler foundation was analyzed by Celep [10]. The static and dynamic analysis of a circular plate on a two-parameter tensonless foundation was recently investigated using Galerkin's approximation technique by Celep and Güler [11]. The problem of tensionless elastic foundation under flexible rectangular Mindlin plates was also studied by Mishra and Chakrabarti [12]. The tensionless character of the foundation was achieved by employing a set of uncorrelated elastic springs attached to each node of the plate and by making these springs active in compression stage only. A unilateral plate contact with the elasto-plastic one-parameter Winkler foundation model was presented by Lewandowski and Świtka [13]. In the paper of Eratll and Aköz [14], a solution for Reissner plates on Winkler foundation based on the Gâteaux derivative theory was formulated. Özçelikörs et al. [15] also used the Gâteaux differential method combined with the classical Hellinger-Reissner and Hu-Washizu variational formulations in order to obtain a solution for interaction of orthotropic Kirchhoff plate and orthotropic Pasternak foundation. The mixed Galerkin-perturbation technique to nonlinear bending analysis of rectangular Reissner-Mindlin plate with free edges, resting on Pasternak elastic foundation, was recently attempted by Shen [16]. In the work of Feng and Owen [17] a coupled finite element and boundary element procedure to analyse a plate-foundation problem was described in which the boundary element equations of the foundation were not explicitly assembled with the finite element equations, but an iterative procedure was proposed to obtain the final coupled solution instead. The discrete singular convolution method was developed by Civalek and Acar [18] for static analysis of thick plates bending on the Pasternak foundation for different boundary conditions and arbitrary edges. 
Analysis of interaction of thick plate with arbitrary layered foundation is a very complex engineering problem. The foundation consist of several layers of varying thickness and the kinematic constraints for each of the layers must be ensured. One of the first satisfactory numerical solution of rectangular plates resting on layered foundatiohn was obtained by Fraser and Wardle [19]. In their paper solutions were presented for the displacements and maximum bending moments for uniformly loaded raft of arbitarary rigidity resting on homogeneous isotropic multi-layered medium. Kolar and Nemec [20] developed a 3D-FEM model allowing for the contribution from the soil medium located outside the area of the plate. In their model, the effect of the reaction of the foundation outside the plate was involved by the use of the elastic springs distributed along the plate. In the model, the deflection outside the contact area between plate and foundation was approximated by the assumed exponential function. Sadecka [21] introduced modifications in the Kolar-Nemec model. In her model infinite elements for modelling the behaviour of layered foundation outside the plate were used. Wang et al. [22] presented a semi-analytical method combined with finite element for analyzing plates on layered soils by applying Hankel transforms. Almeida and Paiva [23] recently proposed the boundary element method to analyze of static soil-pile interaction in layered soil. In their study, the authors Kim, Lim and Cho [24] presented a solution for three-dimensional elastodynamics interaction of surface fundation on a layered half-space in which they adopted a coupling method that combines the finite element for surface foundation and the bounadry element for the layered half-space. In Ai nad Yue [25] the analytical method using the Hankel transforms, combined with the finite difference method, has been recently adopted for analyzing the axially loaded single piles in multilayered non-homogeneous medium subjected to a vertical point load. Andersen and Clausen [26] discussed a BEM solution for dynamic soil-structure interaction (a rigid foundation on a layered subsoil) whereas the solution based on domain-transformation method and the Green's function for layered viscoelastic half-space.

The main aim of this paper is to present a new method for the modelling of multi-layered foundation using zero-thickness interface elements. In Section 2 we begin with short description of the two-parameter foundation model and the finite element procedure in order to determine the stiffness matrices of the finite interface-foundation element. In Section 3 a numerical example is presented in order to illustrate the validity of the method proposed. In the final section some conclusions are drawn.

\section{Finite element PRocedure}

In this section we present short expressions for the element stiffness matrix and the soil reactions based on quadratic Lagrange 9-node Mindlin plate (nodal dof: $w-$ transverse displacement in the direction $z$ and $\theta_{x}, \theta_{y}-$ the normal rotations about the $x$ - and $y$-axis respectively) and 18-node zero-thickness foundation elements [27]. We 
recommend here the nine-node Mindlin plate element of the Lagrange family in which $3 \times 3$ Gauss integration scheme is employed for both the bending, and shear deformation to handle extremely thin plates for very large length-thickness ratios up to $b / t=10^{6}$ [9]. (An alternative proposal is the use of the heterosis element which represents a synthesis of the serendipity type of the interpolation which is used on displacement only, and a lagrangian one on rotations, see Reference [28].)

The present formulation is based on the theory of the plates which enables the transverse shear deformations. In this theory the displacements $w$ and both rotations $\beta_{x}$ and $\beta_{y}$ at the plate midsurface are assumed independent variables. Moreover, the concept of isoparametric $C^{0}$ finite plate element can be directly constructed. According to the small bending theory, the displacement components of a point of coordinates $x$, $y$ and $z$ are

$$
u=-z \beta_{x}(x, y), \quad v=-z \beta_{y}(x, y), \quad w=w(x, y)
$$

where $w$ is the transverse displacement and $\beta_{x}(x, y)$ and $\beta_{y}(x, y)$ are the rotations of the normal to the undeformed middle surface. In the Kirchhoff plate theory shear deformations are excluded, then $\beta_{x}=w_{, x}$ and $\beta_{y}=w_{, y}$, see for details Reference [29].

\subsection{Formulation OF THE FOUNDATION}

A two-parameter model for a plate resting on elastic foundation including a shear effect of the foundation is investigated. In this model the expression relating the pressure and corresponding deflection of the foundation is [2]

$$
p=k_{0} w-k_{1}\left(\frac{\partial^{2} w}{\partial x^{2}}+\frac{\partial^{2} w}{\partial y^{2}}\right)
$$

where $p, w$ and $k_{1}$ are the surface pressure, the transverse deflection, and the shear modulus of the foundation (second foundation parameter) respectively; $k_{0}$ is modulus of subgrade reaction of the soil (first or Winkler foundation parameter).

The strain energy expressions for the Winkler foundation and the energy associated with the second foundation parameter $k_{1}$ are

$$
U_{F}=\frac{1}{2} \int_{A}[w(x, y)]^{T} k_{0}[w(x, y)] \mathrm{d} x \mathrm{~d} y+\frac{1}{2} \int_{A} \gamma_{\mathrm{F}}^{\mathrm{T}} k_{1} \gamma_{\mathrm{F}} \mathrm{d} x \mathrm{~d} y
$$

The second term in the above equation can be regarded as the strain energy in shear associated with the parameter $k_{1}$, where the shear strain vector $\gamma_{\mathrm{F}}$ can be written as 


$$
\gamma_{\mathrm{F}}=\left\{\begin{array}{l}
\frac{\partial w}{\partial x} \\
\frac{\partial w}{\partial y}
\end{array}\right\}
$$

For the foundation elements, the soil tractions and relative soil displacements $w(x, y)$ are evaluated for nodes situated between the top and bottom planes of the interface element; for details we refer to Reference [27]. We express these relative transverse displacements as

$$
w(x, y)=w(x, y)_{\mathrm{TOP}}-w(x, y)_{\mathrm{BOT}}=\mathbf{N w}
$$

where $\mathbf{w}$ is a vector of the nodal transverse displacements of the interface element defined as

$$
\mathbf{w}=\left[\begin{array}{llllllll}
w_{1} & w_{2} & \ldots & w_{9} & w_{10} & w_{11} & \ldots & w_{18}
\end{array}\right]^{\mathrm{T}}
$$

and the matrix $\mathbf{N}$ is given by

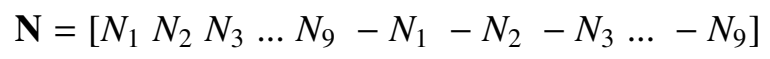

Where $N_{i}$ is a shape function for node $i$. The matrix $\mathbf{N}$ includes non-differentiated shape functions of the thick nine-node plate Mindlin element is given, for example, in [29].

By substituting equation (2.5) into the strain energy expression (equation (2.3)) we obtain the total stiffness matrix of the foundation

$$
\mathbf{K}_{i j}=k_{0} \iint_{A} N_{j} N_{i} d x d y+k_{1} \iint_{A}\left(\frac{\partial N_{j}}{\partial x} \frac{\partial N_{i}}{\partial x}+\frac{\partial N_{j}}{\partial y} \frac{\partial N_{i}}{\partial y}\right) \mathrm{d} x \mathrm{~d} y
$$

Following the isoparametric concept, the stiffness submatrices linking nodes $i$ and $j$ of the interface element related to the first $k_{0}$ and the second foundation parameter $k_{1},\left(\mathbf{K}_{0}\right)_{i j}$ and $\left(\mathrm{K}_{1}\right)_{i j}$ have the form

$$
\left(\mathrm{K}_{0}\right)_{i j}=k_{0} \int_{-1}^{+1} \int_{-1}^{+1} N_{j} N_{i} \operatorname{det} \mathbf{j} \mathrm{d} \xi \mathrm{d} \eta
$$


and

$$
\begin{aligned}
& \left(\mathrm{K}_{1}\right)_{i j}=\int_{-1}^{+1} \int_{-1}^{+1} \frac{k_{1}}{\operatorname{det} \mathbf{j}}\left(\frac{\partial N_{j}}{\partial \xi} \frac{\partial y}{\partial \eta}-\frac{\partial N_{j}}{\partial \eta} \frac{\partial y}{\partial \xi}\right)\left(\frac{\partial N_{i}}{\partial \xi} \frac{\partial y}{\partial \eta}-\frac{\partial N_{i}}{\partial \eta} \frac{\partial y}{\partial \xi}\right) \mathrm{d} \xi \mathrm{d} \eta+ \\
& \int_{-1}^{+1} \int_{-1}^{+1} \frac{k_{1}}{\operatorname{det} \mathbf{j}}\left(-\frac{\partial N_{j}}{\partial \xi} \frac{\partial x}{\partial \eta}+\frac{\partial N_{j}}{\partial \eta} \frac{\partial x}{\partial \xi}\right)\left(-\frac{\partial N_{i}}{\partial \xi} \frac{\partial x}{\partial \eta}+\frac{\partial N_{i}}{\partial \eta} \frac{\partial x}{\partial \xi}\right) \mathrm{d} \xi \mathrm{d} \eta
\end{aligned}
$$

where the determinant of the transformation Jacobian matrix is expressed as

$$
\operatorname{det} \mathbf{j}=\frac{\partial x}{\partial \xi} \frac{\partial y}{\partial \eta}-\frac{\partial x}{\partial \eta} \frac{\partial y}{\partial \xi}
$$

The reactions of foundation related to the first parameter $k_{0}$ and the second one $k_{1}$, that is the transverse force $W$ and the shear forces (at the node $i$ ) $\mathbf{T}=\left(T_{x}, T_{y}\right)$ respectively, can be expressed as [9]

$$
(W)_{i}=k_{0} \int_{-1}^{+1} \int_{-1}^{+1} N_{i} w_{i} \operatorname{det} \mathbf{j} \mathrm{d} \xi \mathrm{d} \eta
$$

and

$$
\begin{aligned}
& \left(T_{x}\right)_{i}=k_{1} \int_{-1}^{+1} \int_{-1}^{+1}\left(\frac{\partial N_{i}}{\partial \xi} \frac{\partial y}{\partial \eta}-\frac{\partial N_{i}}{\partial \eta} \frac{\partial y}{\partial \xi}\right) w_{i} \mathrm{~d} \xi \mathrm{d} \eta \\
& \left(T_{y}\right)_{i}=k_{1} \int_{-1}^{+1} \int_{-1}^{+1}\left(\frac{\partial N_{i}}{\partial \eta} \frac{\partial x}{\partial \xi}-\frac{\partial N_{i}}{\partial \xi} \frac{\partial x}{\partial \eta}\right) w_{i} \mathrm{~d} \xi \mathrm{d} \eta
\end{aligned}
$$

in which the expressions $\partial x / \partial \xi, \partial x / \partial \eta, \partial y / \partial \xi$ and $\partial y / \partial \eta$ are components of the Jacobian matrix.

The numerical integration of equations (2.9) and (2.10) for the quadrilateral element of rectangular shape with $3 \times 3$ sampling points leads to

$$
\left(\mathrm{K}_{0}\right)_{i j}=\sum_{p=1}^{3} \sum_{q=1}^{3} N_{i}^{T}\left(\xi_{p}, \eta_{q}\right) k_{0} N_{j}\left(\xi_{p}, \eta_{q}\right) \operatorname{det} \mathbf{j}\left(\xi_{p}, \eta_{q}\right) W_{p} W_{q}
$$


and

$$
\begin{aligned}
& \left(\mathrm{K}_{1}\right)_{i j}=\frac{b^{2}}{4} \sum_{p=1}^{3} \sum_{q=1}^{3} \frac{k_{1}}{\operatorname{det} \mathbf{j}\left(\xi_{p}, \eta_{q}\right)}\left(N_{i, \xi}\right)^{2}\left(\xi_{p}, \eta_{q}\right) W_{p} W_{q}+ \\
& \frac{a^{2}}{4} \sum_{p=1}^{3} \sum_{q=1}^{3} \frac{k_{1}}{\operatorname{det} \mathbf{j}\left(\xi_{p}, \eta_{q}\right)}\left(N_{i, \eta}\right)\left(\xi_{p}, \eta_{q}\right) W_{p} W_{q}
\end{aligned}
$$

with $W_{p}$ and $W_{q}$ being the integration weights.

The stiffness matrices of the interface element related to the first, $k_{0}$, and the second parameter, $k_{1}$, (equations (2.15 and (2.16)) were integrated, and their explicit forms are given in Reference [9].

\subsection{FOUNDATION PARAMETERS $k_{0}$ AND $k_{1}$}

The two parameters $k_{0}$ and $k_{1}$ in terms of the elastic contstants and the dimensions of the plate and the soil foundation were evaluated by Vallabhan, Straughan and Das [4]. These parameters applied to the foundation with a finite depth of soil, $h$, can be defined by

$$
k_{0}=\frac{E_{0}}{\left(1-v_{0}^{2}\right)} \int_{0}^{h} \Psi^{\prime}(z)^{2} \mathrm{~d} z
$$

and

$$
k_{1}=\frac{E_{0}}{2\left(1+v_{0}\right)} \int_{0}^{h} \Psi^{2}(z) \mathrm{d} z
$$

with the mode function $\Psi(z)$ which can be obtained by using variational principles and applying the proper boundary conditions, such as $\Psi(0)=1$ and $\Psi(h)=0$, so due to Vallabhan et al. [4] this function is given as

$$
\Psi(z)=\frac{\sinh \gamma \frac{h-z}{h}}{\sinh \gamma}
$$

The generalized modulus of elasticity, $E_{0}$, and the Poisson ratio, $v_{0}$, are defined by

$$
E_{0}=\frac{E_{F}}{1-v_{F}^{2}}, \quad v_{0}=\frac{v_{F}}{1-v_{F}}
$$


where $E_{F}$ and $v_{F}$ are the modulus of elasticity and Poisson's ratio of the foundation, respectively, and $h$ is the foundation depth. If the elasticity modulus $E_{S}$ is constant through the thickness of the foundation and using the mode function $\Psi(z)$ as given in equation (2.19), the foundation parameters $k_{0}$ (equation (2.17)) and $k_{1}$ (equation (2.18)) become

$$
k_{0}=\frac{E_{F}\left(1-v_{F}\right)}{8 h\left(1+v_{F}\right)\left(1-2 v_{F}\right)} \frac{2 \gamma \sinh 2 \gamma+4 \gamma^{2}}{\sinh ^{2} \gamma}
$$

and

$$
k_{1}=\frac{E_{F} h}{16 \gamma^{2}\left(1+v_{F}\right)} \frac{2 \gamma \sinh 2 \gamma-2 \gamma^{2}}{\sinh ^{2} \gamma}
$$

However, these parameters also depend on a coefficient, $\gamma$, which represents the rate of decrease of the displacement and the normal stresses in the vertical direction in the soil foundation. According to Vallabhan, Straughan and Das [4] the parameter $\gamma$ can be expressed as

$$
\gamma^{2}=h^{2} \frac{\left(1-2 v_{s}\right)}{2\left(1-v_{s}\right)} \frac{\int_{-\infty}^{+\infty} \int_{-\infty}^{+\infty}\left\{\left(\frac{\partial w(x, y)}{\partial x}\right)^{2}+\left(\frac{\partial w(x, y)}{\partial x}\right)^{2}\right\} \mathrm{d} x \mathrm{~d} y}{\int_{-\infty}^{+\infty} \int_{-\infty}^{+\infty} w^{2}(x, y) \mathrm{d} x \mathrm{~d} y}
$$

For plates on the elastic foundation, the dimensionless parameter, $\gamma$, can be evaluated using an iterative procedure after the determination of the vertical displacement $w(x, y)$. At the end of every iteration a criterion is monitored to see whether the iterative solution converged within the tolerance.

In order to analyze cases in which the modulii of elasticity of the foundation $E_{s}$ (equation (1.1)) can vary linearly in the vertical direction from $E_{1}$ at the top to $E_{2}$ at the bottom, expressions for the foundation parameters $k_{0}$ and $k_{1}$ can be modified to the following form

$$
k_{0}=\frac{1-v_{F}}{8 h\left(1+v_{F}\right)\left(1-2 v_{F}\right)} \frac{E_{1}\left(2 \gamma \sinh 2 \gamma+4 \gamma^{2}\right)+\left(E_{2}-E_{1}\right)\left(\cosh 2 \gamma-1+4 \gamma^{2}\right)}{\sinh ^{2} \gamma}
$$

and

$$
k_{1}=\frac{h}{16 \gamma^{2}\left(1+v_{F}\right)} \frac{E_{1}\left(2 \gamma \sinh 2 \gamma-2 \gamma^{2}\right)+\left(E_{2}-E_{1}\right)\left(\cosh 2 \gamma-1-2 \gamma^{2}\right)}{\sinh ^{2} \gamma}
$$


When the elasticity modulus $E_{s}$ (equation (1.2)) changes quadratically through the depth of the foundation, the foundation parameters $k_{0}$ and $k_{1}$ can be evaluated by

$$
k_{0}=\frac{1-v_{F}}{\left(1+v_{F}\right)\left(1-2 v_{F}\right)} \frac{3\left[E_{2}+E_{1}\left(2 \gamma^{2}-1\right)\right] \sinh 2 \gamma+\left[E_{2}\left(4 \gamma^{2}-3\right)+E_{1}\left(3+2 \gamma^{2}\right)\right] 2 \gamma}{24 h \gamma \sinh ^{2} \gamma}
$$

and

$$
k_{1}=\frac{h}{\left(1+v_{F}\right)} \frac{3\left[E_{2}+E_{1}\left(2 \gamma^{2}-1\right)\right] \sinh 2 \gamma-\left[E_{2}\left(4 \gamma^{2}+3\right)+E_{1}\left(2 \gamma^{2}-3\right)\right] 2 \gamma}{48 \gamma^{3} \sinh ^{2} \gamma}
$$

\section{NUMERICAL APPLICATION}

A computer program for the finite element analysis of bending Mindlin plates resting on a two-parameter elastic layered foundation is used to verify the accuracy of the proposed method. The finite element model allows to add a few foundation layers (Figure 1).

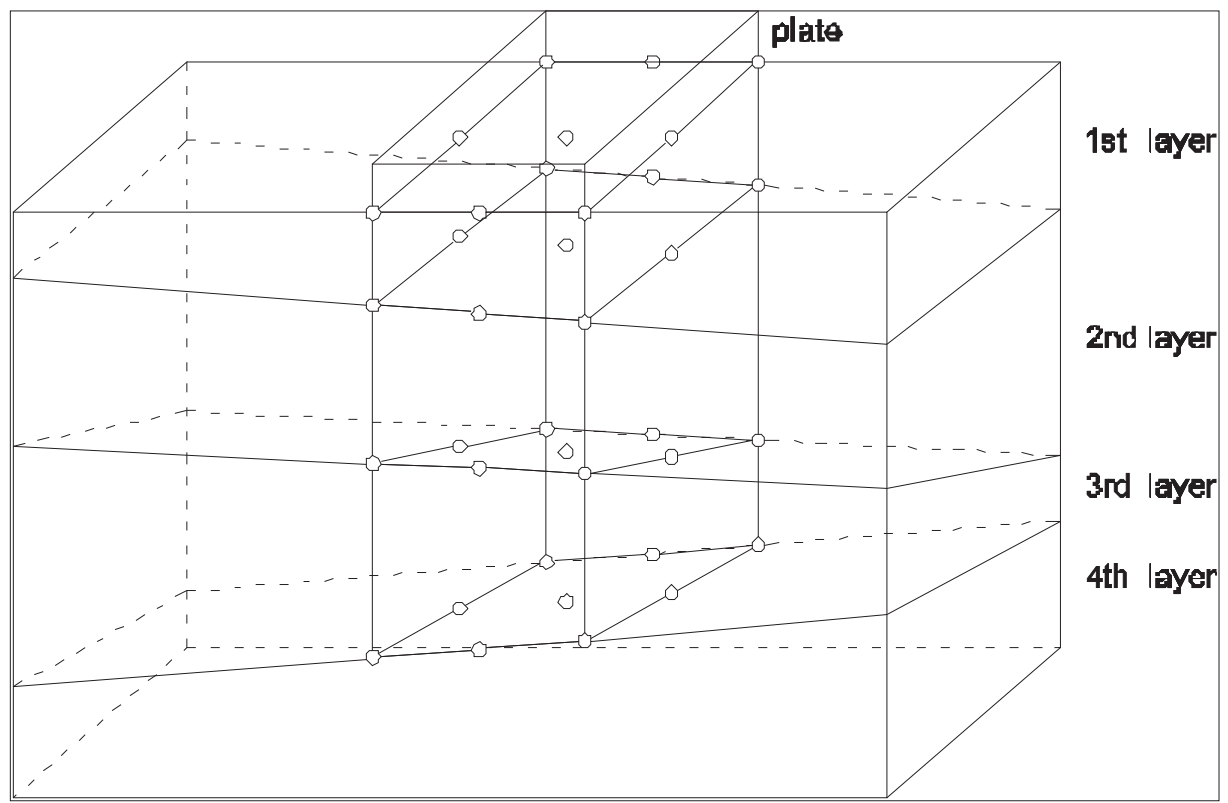

Fig. 1. The finite element model of the layered foundation.

Rys. 1. Model podłoża wielowarstwowego za pomocą elementów skończonych 


\subsection{Free rectangular plate on an unilateral homogeneous foundation}

A free rectangular plate of the size of $9.6 \times 7.2 \mathrm{~m}$ and thickness of $t=0.2 \mathrm{~m}$ resting on a two-parameter homogeneous soil medium subjected to uniformly distributed load $q=1 \mathrm{MPa}$ on a central (painted in grey) square (Figure 2) is considered first.

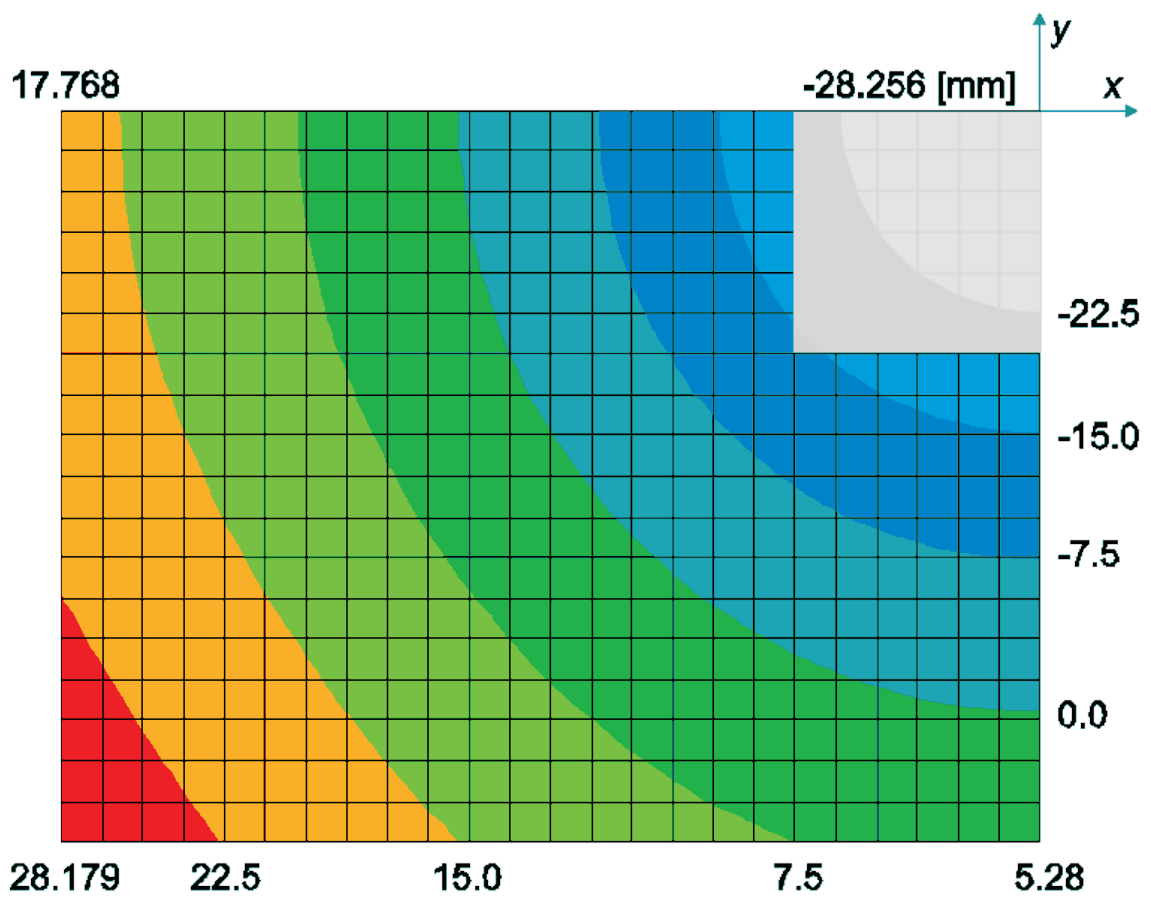

Fig. 2. Free rectangular plate on an unilateral Winkler foundation; (for $w>0[\mathrm{~mm}]$ passive contact zone - separation or loss of contact).

Rys. 2. Pływająca prostokątna płyta na jednostronnym podłożu Winklera; $(w>0[\mathrm{~mm}]-$ kontakt pasywny - separacja lub utarata kontaktu)

Due to the symmetry only the quarter of the plate is taken into account. The $18 \times 24$ mesh consists of 432 quadratic Lagrange 9-node Mindlin plate elements. The calculations are performed for the first (Winkler) $k_{0}$ and the second foundation parameter $k_{1}$. Both the foundation parameters are assumed to be dependent on material properties and the depth of the soil medium (see equations (2.21) and (2.22)) as well as on the dimensionless parameter $\gamma$ given by equation (2.23). The calculations are performed for the foundation depth, $h=5 \mathrm{~m}$, the Poisson ratios $v_{s}=0.45$ and $v_{p}=0.17$ for the soil (foundation) and plate, respectively. The Young modulus of the plate is assumed $E=23 \mathrm{GPa}$. In order to enable comparison of our results with the first parameter only, with those reported by Lewandowski and Świtka [13] and Jirousek at al. [30], we made calculations for $E_{1}=E_{2}=42 \mathrm{MPa}$ and $\gamma$ as given in Table 1 . 
The results are in close agreement with those by Jirousek at al. [30], solved by a hybrid-Trefftz approach and by assuming the Winkler conditions there.

The settlement of the plate along $x$-axis for uniformly distributed load [mm],

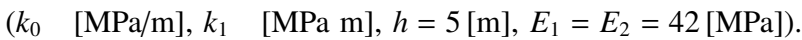

Obniżenie płyty wzdłuż osi w przypadku obciążenia stałym ciśnieniem [mm], $\left(k_{0} \quad[\mathrm{MPa} / \mathrm{m}], k_{1} \quad[\mathrm{MPa} \mathrm{m}], h=5[\mathrm{~m}], E_{1}=E_{2}=42[\mathrm{MPa}]\right)$

\begin{tabular}{|c|c|c|c|}
\hline$x[\mathrm{~m}]$ & $\begin{array}{c}\text { Winkler model } \\
\left(\left(k_{0}=20, k_{1}=0\right)\right.\end{array}$ & $\begin{array}{c}\gamma=1.1316 \\
\left(k_{0}=32.7862, k_{1}=30.0426\right)\end{array}$ & $\begin{array}{c}\gamma=2.1327 \\
\left(k_{0}=39.1322, k_{1}=16.4144\right)\end{array}$ \\
\hline 0.0 & -28.256 & -12.962 & -5.234 \\
\hline 0.6 & -24.571 & -10.978 & -4.759 \\
\hline 1.2 & -19.961 & -7.952 & -3.269 \\
\hline 1.8 & -12.272 & -4.283 & -1.328 \\
\hline 2.4 & -4.674 & -0.427 & 0.261 \\
\hline 3.0 & 1.459 & 3.190 & 1.389 \\
\hline 3.6 & 7.368 & 6.487 & 2.474 \\
\hline 4.2 & 12.491 & 8.423 & 3.427 \\
\hline 4.8 & 17.768 & 9.661 & 4.189 \\
\hline
\end{tabular}

It can be noted from Table 1 that, for larger parameter $k_{0}$, the settlement of foundation is smaller. The larger parameter $\gamma$ the smaller the active contact zone $(w<0)$, see Figure 3. This is the result of resistance of the foundation due to influence of the second parameter. In particular, for very small values of the parameter $k_{1}$ the behaviour of the foundation approaches the Winkler foundation model for which the second parameter $k_{1}$ is assumed zero. For the Winkler approach, the value of maximum settlement at the center of the plate is equal to $w=28.256[\mathrm{~mm}]$ (see another results from Table 1 and Figure 3 to compare).

\subsection{Free rectangular plate on a layered foundation}

A free rectangular plate of the size $9.144 \times 12.192 \mathrm{~m}$ and thickness of $0.1524 \mathrm{~m}$, subjected to uniformly distributed load, were analyzed next (Figure 4). The size of the fundation and its depth are: $27.432 \times 30.48 \mathrm{~m}$ and $h=3.048 \mathrm{~m}$. It was assumed the Poisson ratio equals to $v_{F}=0.25$ and $v_{p}=0.20$ for the soil and plate, respectively. The same problem in which the elasticity modulus of the foundation $E_{2}$ at the bottom is equal to $E_{1}$ at the top was considered by Çelik and Saygun [6] and Vallabhan at al. [4].

The results are obtained for $E_{1}=68950 \mathrm{kN} / \mathrm{m}^{2}$ and $E_{p}=20685 \mathrm{MN} / \mathrm{m}^{2}$ for the top of the foundation and the plate, respectively. The foundation parameters $k_{0}$ and $k_{1}$ are assumed dependent on material properties and the depth of the foundation, as well as on the dimensionless parameter $\gamma$ given by equation (2.23). The vertical displacements at the centre of the plate are shown in Table 2. 


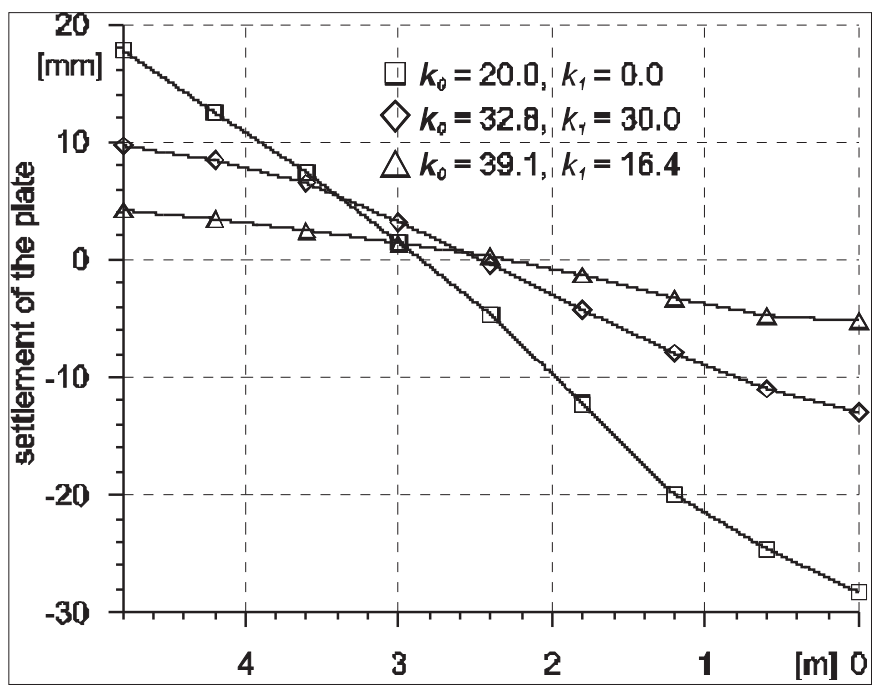

Fig. 3. The settlement of the plate along $x$-axis for uniformly distributed load. Rys. 3. Obniżenie płyty wzdłuż osi $x$ w przypadku obciążenia stałym ciśnieniem

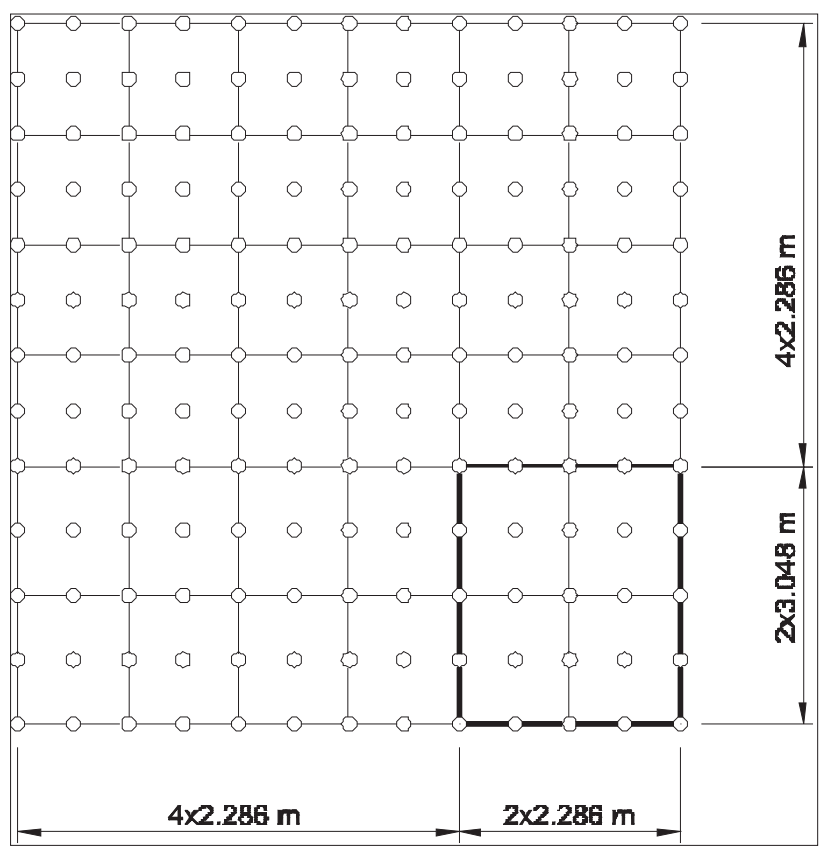

Fig. 4. Free rectangular plate on elastic foundation (only one quadrant is discretized). Rys. 4. Pływająca prostokatna płyta na podłożu sprężystym (pokazano tylko jedną ćwiartkę) 


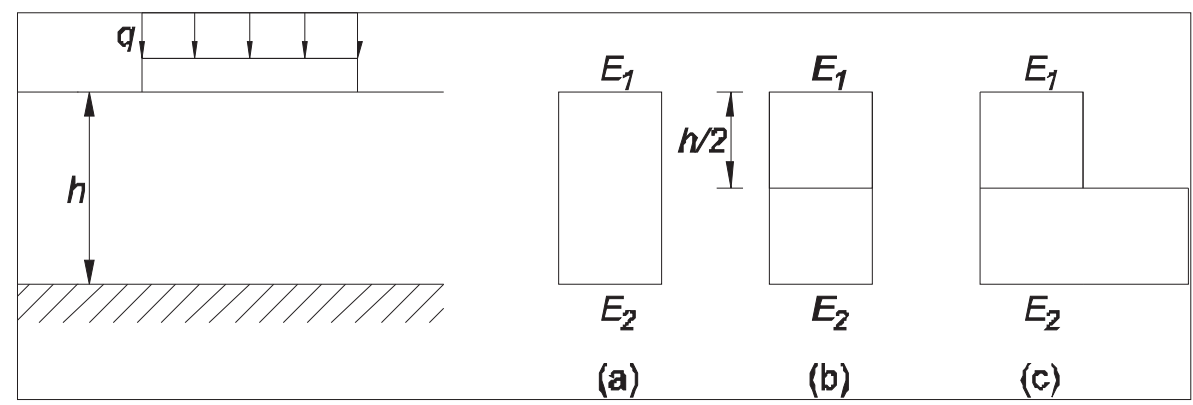

Fig. 5. Free plate: (a) one layer, $E_{2}=E_{1}$, (b) two layers, $E_{2}=E_{1}$, (c) two layers, $E_{2}=2 E_{1}$. Rys. 5. Płyta pływająca, $E_{2}=E_{1}$, (b) dwie warstwy, $E_{2}=E_{1}$, (c) dwie warstwy, $E_{2}=2 E_{1}$

Table 2

The vertical displacement at the centre of the plate for uniformly distributed load. Pionowe przemieszczenie centralnego punktu płyty w przypadku obciążenia stałym ciśnieniem

\begin{tabular}{|c|l|c|c|c|c|}
\hline$h(\mathrm{~m})$ & Reference & $k_{0}\left(\mathrm{kN} / \mathrm{m}^{3}\right)$ & $k_{1}(\mathrm{kN} / \mathrm{m})$ & $\gamma$ & $w(\mathrm{~cm})$ \\
\hline 3.048 & $\begin{array}{l}\text { Present, } \\
\text { Figure 5(a) }\end{array}$ & 87212 & 0.5844 & 0.0734 \\
\cline { 2 - 6 } & $\begin{array}{l}\text { Present, } E_{2}=E_{1}, \\
\text { Figure 5(b) }\end{array}$ & $\begin{array}{c}54423 / 54423 \\
\text { top/bottom }\end{array}$ & $\begin{array}{c}40895 / 40895 \\
\text { top/bottom }\end{array}$ & 0.5844 & 0.0733 \\
\cline { 2 - 6 } & $\begin{array}{l}\text { Present, } E_{2}=2 E_{1}, \\
\text { Figure 5(c) }\end{array}$ & $\begin{array}{c}54433 / 108865 \\
\text { top/bottom }\end{array}$ & $\begin{array}{c}39825 / 79650 \\
\text { top/bottom }\end{array}$ & 0.5947 & 0.0609 \\
\hline
\end{tabular}

3.3. Free square plate on a layered foundation (Figure 6)

A square thick plate of length $a=5 \mathrm{~m}$ and thickness of $t=0.25 \mathrm{~m}$ or $t=1.25 \mathrm{~m}$ resting on two-layered foundation of size $10 \times 10 \mathrm{~m}$ is considered. The same example was also analyzed by Sadecka [21]. The numerical solution obtained by a weighting method for the isotropic semi-infinite medium was presented by Fraser and Wardle [19]. In the Kolar-Nemec's model, the deflection outside the contact area between plate and foundation is approximated by the assumed exponential function. Sadecka introduced modifications in the Kolar-Nemec's model. In her model infinite elements were used for modelling of the layered foundation outside the plate. A quarter of plate division into finite elements is shown in Figure 6. The whole plate is loaded by a uniformly distributed load $q=1 \mathrm{MPa}$.

The foundation is divided into two layers of thickness $h_{2}=3 \mathrm{~m}$ and $h_{1}=7 \mathrm{~m}$ for the top and the bottom, respectively (Figure 7).

The Poisson's ratio for both the layers is $v_{F}=0.3$. The material properties of the plate are as follows: Young's modulus $E_{p}=21000 \mathrm{MPa}$, Poisson's ratio $v_{p}=0.167$. The generalized modulus of elasticity from equation (2.20) $E_{0}=E_{p} / 500$ and $E_{0}=$ $E_{p} / 1000$ are chosen for calculations. According to equations (2.21) and (2.22), the following foundation parameters are obtained for both the foundation layers: in the 


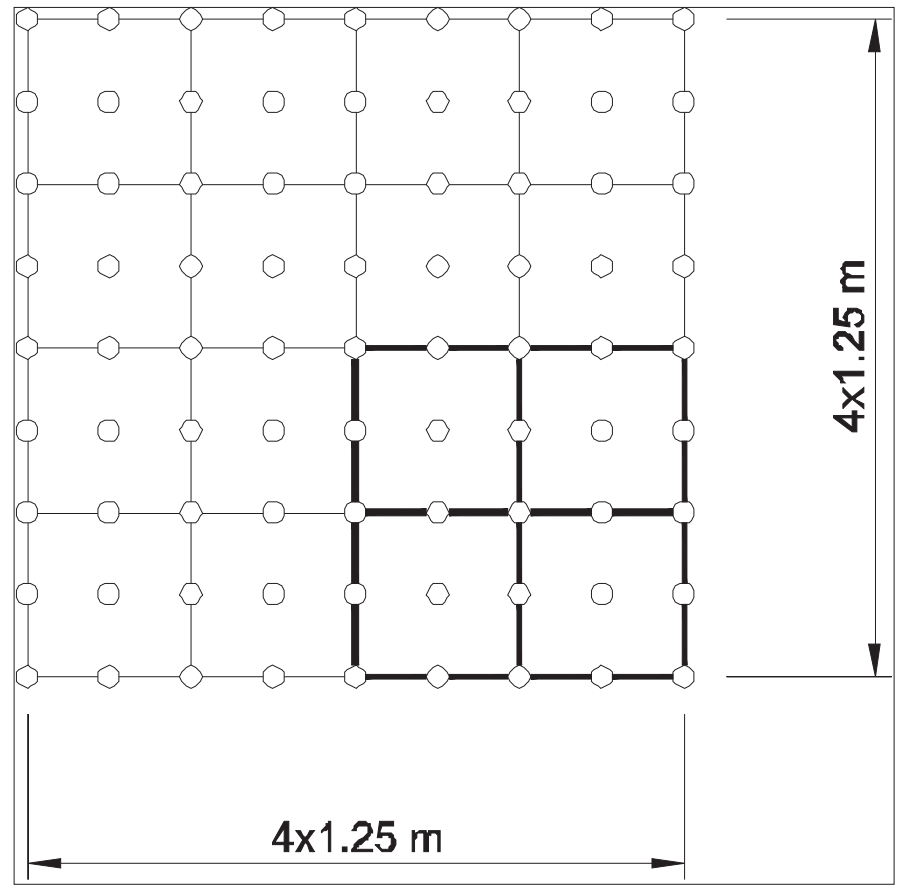

Fig. 6. Arrangement of square plate on elastic foundation. Rys. 6. Aranżacja płyty kwadratowej na podłożu sprężystym

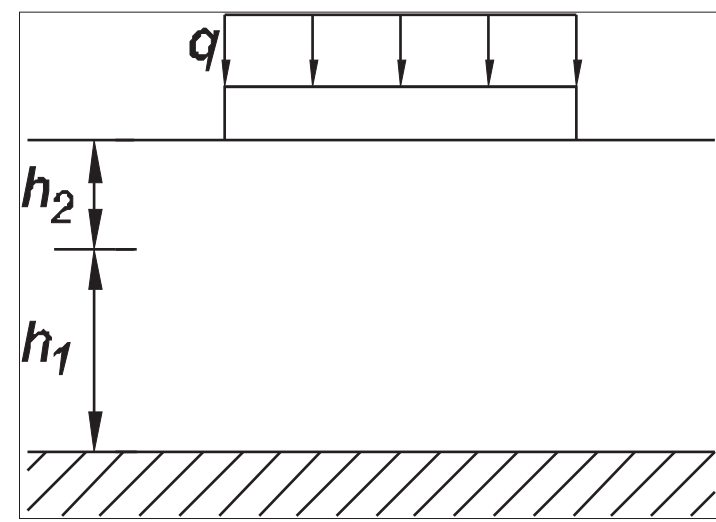

Fig. 7. Thick plate on two-layered foundation. Rys. 7. Płyta gruba na podłożu dwuwarstwowym 
case of $E_{p} / E_{0}=500, k_{0}=5.291 \mathrm{MPa} / \mathrm{m}$ and $k_{1}=61.369 \mathrm{MPam}$, while in the case of $E_{p} / E_{0}=1000, k_{0}=2.646 \mathrm{MPa} / \mathrm{m}$ and $k_{1}=30.684 \mathrm{MPam}$.

Selvadurai [31] suggests the following form for the modulus of foundation in the case of the Winkler model

$$
k_{0}=\frac{2 E_{F}}{a \cdot \ln (1+2(H / a))}
$$

where $H=h_{1}+h_{2}$ is the thickness of the foundation and $a$ is the length of the plate.

Table 3

The vertical displacement of the plate for uniformly distributed load (in [mm]). Pionowe przemieszczenie płyty w przypadku obciążenia stałym ciśnieniem (w [mm])

\begin{tabular}{|r|c|c|c|c|c|c|}
\hline$E_{p} / E_{0}$ & $(t / a)$ & $\gamma$ & $\begin{array}{c}\text { present } \\
\text { Winkler }\end{array}$ & $\begin{array}{c}\text { present } \\
\text { two parameter }\end{array}$ & Sadecka [21] & Fraser and Wardle [19] \\
\hline 500 & 0.05 & 1.1249 & 10.1074 & 7.6014 & 7.8040 & 10.61 \\
\hline 500 & 0.25 & 1.1249 & 9.8243 & 5.1059 & 5.3538 & 7.77 \\
\hline 1000 & 0.05 & 1.1254 & 19.9589 & 14.4128 & 14.6173 & 21.21 \\
\hline 1000 & 0.25 & 1.1254 & 19.6451 & 10.4276 & 10.5891 & 15.54 \\
\hline
\end{tabular}

According to equation (30), for $E_{p} / E_{0}=500$, the Winkler parameter $k_{0}$ equals $9.4990 \mathrm{MPa} / \mathrm{m}$, while in the case of $E_{p} / E_{0}=1000 k_{0}$ it is equal to $4.7495 \mathrm{MPa} / \mathrm{m}$ for both the foundation layers. As expected, the maximum value of the settlement at the center of the plate for the Winkler approach is always greater than for the two-parameter one. Table 3 summarizes the results for both, the one- and two-parameter foundation models. The results obtained for the two-parameter model are closer to the solution of Sadecka [21] than the results obtained for semi-infinite medium by Fraser and Wardle [19].

\subsection{Free square Plate on a four-layer foundation (Figure 8)}

A thick plate of size $10 \times 10 \mathrm{~m}$ and thickness of $t=0.5 \mathrm{~m}$ resting on a four-layer foundation of size $20 \times 20 \mathrm{~m}$ is considered. The example was adopted from Fraser and Wardle [19] and Wang et al. [22] where results for elastic halfspace were given. The material constants of the plate are as follows: Young's modulus $E_{p}=15000 \mathrm{MPa}$, Poisson's ratio $v_{p}=0.2$. Due to the symmetry, only a quarter of the square plate is taken into consideration. The whole plate was loaded by a uniformly distributed load $q=0.1 \mathrm{MPa}$.

The foundation is divided into four layers of thickness $10 \mathrm{~m}$ (see Figure 9). The Poissons' ratio for all layers is equal to $v_{F}=0.3$. The Youngs' modulus, the foundation parameters $k_{0}$ and $k_{1}$ are given in Figure 9. The parameter $\gamma$ is obtained to be equal to 1.2481 for each layer. 


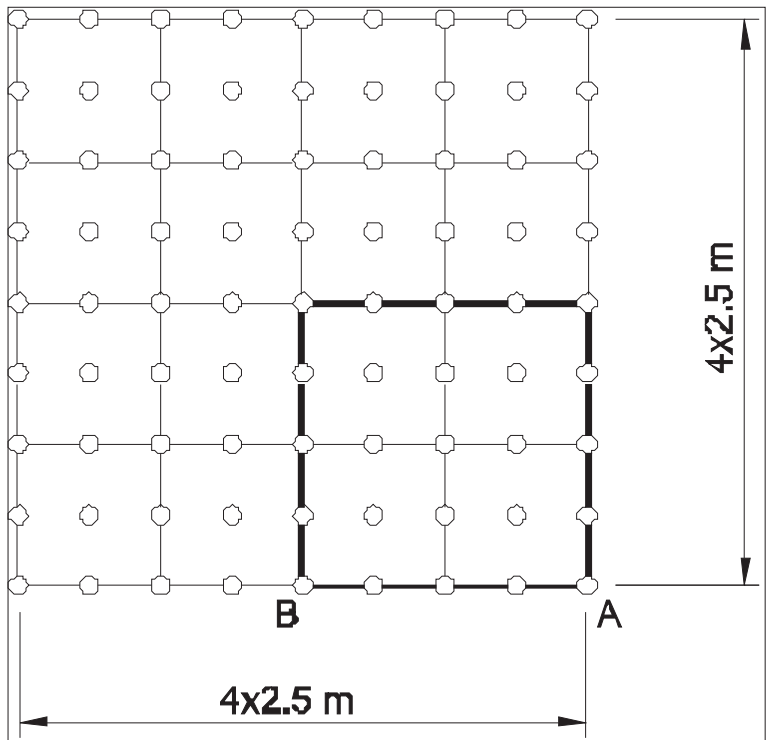

Fig. 8. Finite element discretization of square plate Rys. 8. Siatka elementów skończonych płyty kwadratowej

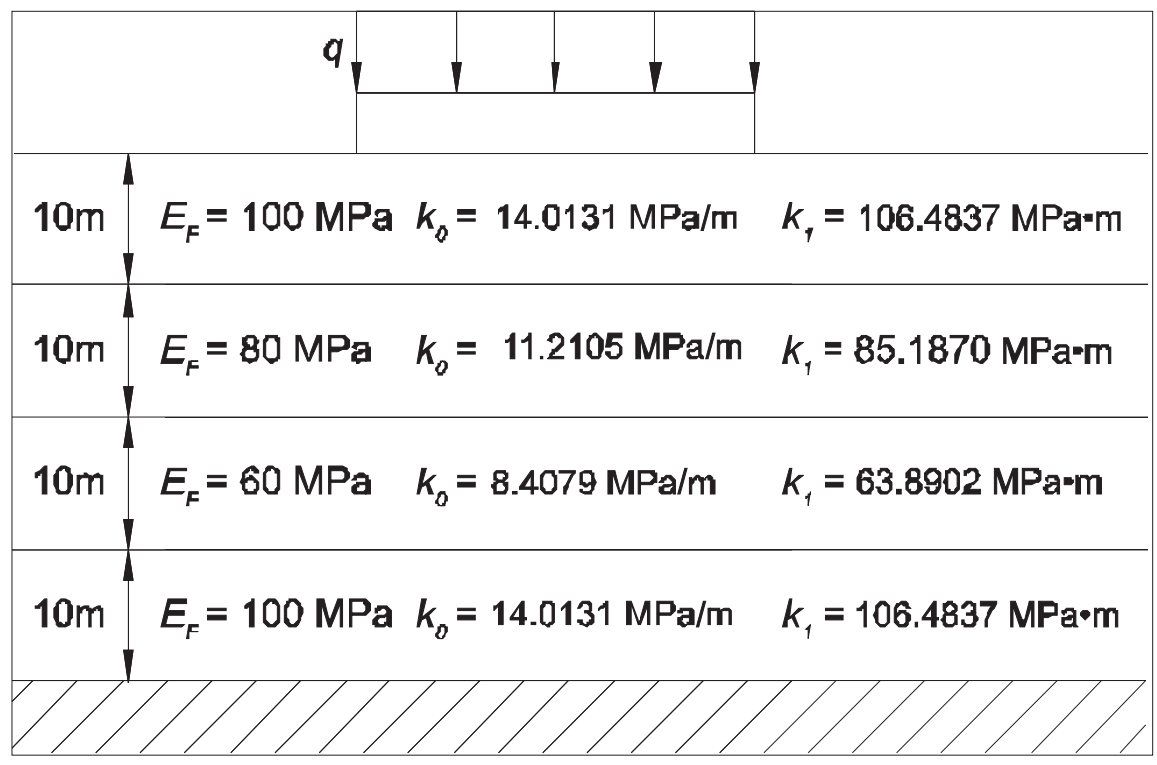

Fig. 9. Thick plate on four-layered foundation. Rys. 9. Płyta gruba na podłożu czterowartwowym 
The vertical displacement of the plate for uniformly distributed load (in [mm]).

Pionowe przemieszczenie płyty w przypadku obciążenia stałym ciśnieniem (w [mm])

\begin{tabular}{|c|c|c|c|c|}
\hline $\begin{array}{c}\text { Point } \\
\text { of plate }\end{array}$ & Present & $\begin{array}{c}\text { Wang at al.[22] } \\
\text { numerical }\end{array}$ & $\begin{array}{c}\text { Fraser and Wardle [19] } \\
\text { numerical }\end{array}$ & $\begin{array}{c}\text { Fraser and Wardle [19] } \\
\text { equivalent }\end{array}$ \\
\hline A & 0.0102 & 0.0120 & 0.0114 & 0.0107 \\
\hline B & 0.0071 & 0.0089 & 0.0087 & 0.0078 \\
\hline
\end{tabular}

The results are compared with those reported by Wang at al. [22], and the numerical results presented by Fraser and Wardle [19] (Table 4). The result are in good agreement with both the numerical results of the other authors.

\section{Conclusions}

The problem of bending plate resting on the two-parameter layered foundation was solved by using the interface elements of zero-thickness. The adopted model can be employed to analyze thick plates resting on foundation with any type of common boundary conditions and loading combinations. The method proposed may also take account of the surrounding effect outside the plate, as well as the unilateral contact conditions between the plate and foundation. A good agreement with the other results reported in the literature is worth noting.

\section{REFERENCES}

1. M.M. Filonenko-Borodich, Some approximate theories of elastic foundation[in Russian], Uchenyie Zapiski Moskovskogo Gosudarstvennogo Universiteta, Mekhanika, 46, 3-18, 1940.

2. P.L. Pasternak, New method of calculation for flexible substructures on two-parameter elastic foundation [in Russian], Gosudarstvennoe Izdatelstvo Literatury po Stroitelstvu i Architekture, Moskau 1954; 1-56 (1954).

3. V.Z. Vlasov, N.N. Leont'ev, Beams, plates and shells on elastic foundations [in Russian], GIFML: Moskau, 1960.

4. C.V.G. Vallabhan, A.T. Daloglu, Consistent FEM-Vlasov model for plates on layered soil. Journal of Structural Engineering ASCE, 125(1), 108-113, 1999.

5. M. Çelik, M. Omurtag, Determination of the Vlasov foundation parameters - quadratic variation of elasticity modulus - using FE analysis. Structural Engineering and Mechanics, 19(6), 619-637, 2005.

6. M. ÇELIK, A. SAYGUN, A method for the analysis of plates on a two-parameter foundation. International Journal of Solids and Structures, 36, 2891-2915, 1999.

7. K. Ozgan, M. Omurtag, Alternative plate elements for the analysis of thick plates on elestic foundation. Structural Engineering and Mechanics, 26(1), 69-86, 2007.

8. K. Ozgan, A.T. Daloglu, Effect of transverse shear strans on plates resting on elastic foundation using modified Vlasov model. Thin-Walled Structures, 46, 1236-1250, 2008.

9. R. Buczkowski, W. Torbacki, Finite element modelling of thick plates on two-parameter elastic foundation. International Journal for Numerical and Analytical Methods in Geomechanics, 25(14), 1409-1427, 2001. 
10. Z. CELEP, Rectangular plates resting on tensionless elastic foundation. Journal of Engineering Mechanics ASCE, 114(12), 2083-2092, 1988.

11. Z. Celep, K. GüLER, Axisymmetric forced vibrations of an elastic free circulaer plate on tensionless two parameter foundation. Journal of Sound and Vibration 301, 495-509, 2007.

12. R.C. Mishra, S.K. Chakrabarti, Rectangular plates resting on tensionless elastic foundation: some new results. Journal of Engineering Mechanics ASCE, 122(4), 385-387, 1996.

13. R. Lewandowski, R. ŚwitKa, Unilateral plate contact with the elastic-plastic Winkler - type foundation. Computers \& Structures, 39(6), 641-651, 1983.

14. N. ERatll, A.Y. Акӧz, The mixed finite element formulation for the thick plates on elastic foundations. Computers \& Structures, 65(4), 515-529, 1997.

15. Y. Özçelikörs, M.H. Omurtag, H. Demir, Analysis of orthotropic plate-foundation interaction by mixed finite element formulation using Gâteaux differential. Computers \& Structures, 62(1), 93-106, 1997.

16. H.S. SHEN, Nonlinear bending of Reissner-Mindlin plates with free edges under transverse and in-plane loads and resting on elastic foundations. International Journal of Mechanical Sciences, 41, 845-864, 1999.

17. Y.T. Feng, D.R.J. Owen, Iterative solution of coupled FE/BE discretizations for plate-foundation interaction problems. International Journal for Numerical Methods in Engineering, 39, 1889-1901, 1996.

18. Ö Civalek, M.H. Acar, Discrete singular convolution method for the analysis of Mindlin plates on elestic foundations. International Journal of Pressure Vessels and Piping, 84, 527-535, 2007.

19. R.A. Fraser, L.J. WardLE, Numerical analysis of elastic foundations. Geotechnique, 26, 613-630, 1976.

20. V. Kolar, I. Nemec, Modeling of soil-structure interaction. Elsevier: Amsterdam, 1989.

21. L. SADECKA, Refined model for analysis of plates on elastic foundations. Computers \& Structures, 76, 603-610, 2000.

22. Y.H. Wang, L.G. Tham, Y. Tsui, Z.Q. Yue, Plate on layered foundation analyzed by a semi analytical and semi-numerical method. Computers and Geotechnics, 30, 409-418, 2003.

23. V.S. Almeida, J.B. Paiva, Static analysis of soil/pile interaction in layered soil by BEM/BEM coupling. Advances in Engineering Software, 38, 835-845, 2008.

24. М.К. Кім, Y.M. Liм, W.Y. Сно, Three dimensinal dynamic response of surface foundation on layered half-space. Engineering Structures, 23, 1427-1436, 2001.

25. Z.Y. AI, Z.Q. YUE, Elastic analysis of axially loaded single pile in multilayered soils. International Journal of Engineering Science, 47(11-12), 1079-1088, 2009.

26. L. Andersen, J. Clausen, Impedance of surface footings on layered ground. Computers \& Structures, 86, 72-87, 2008.

27. R. Buczкоwsкi, 21-node hexahedral isoparametric element for analysis of contact problems. Communications in Numerical Methods in Engineering, 14(7), 681-692, 1998.

28. R.K.N.D. Rajapakse, A.P.S. Selvadurai, On the performance of Mindlin plate elements in modelling plate-elastic medium interaction: a comparative study. International Journal for Numerical Methods in Engineering, 23, 1229-1244, 1986.

29. E. Hinton,D.R.J. Owen, Finite Elements in Plasticity: Theory and Practice. Pineridge Press: Swansea, 1980.

30. J. Jirousek, A.P. Zieliński, A. Wróblewski, T-element analysis of plates on unilateral elastic Winklertype foundation. Computer Assisted Mechanics and Engineering Sciences, 8, 343-358, 2001.

31. A.P.S. Selvadurai, Elastic analysis of soil-foundation interaction. Elsevier: North-Holland, 1979. 


\section{APPENDIX: TENSIONLESS FOUNDATION: ITERATIVE SOLUTION PROCEDURE}

The solution of the problem of tensionless foundation is obtained by the incremental iterative Newton-Raphson procedure which goes as follows.

(i) contact conditions

$$
w(x, y)=\left(\left(\mathbf{w}^{B}+\Delta \mathbf{w}^{B}\right)-\left(\mathbf{w}^{A}-\Delta \mathbf{w}^{A}\right)\right) \mathbf{n}-g_{0} \geq 0 \Rightarrow W=k_{0} \iint_{A}[w(x, y)] \mathrm{d} x \mathrm{~d} y \leq 0
$$

(active node),

where

$$
w(x, y)=\left(\left(\mathbf{w}^{B}+\Delta \mathbf{w}^{B}\right)-\left(\mathbf{w}^{A}-\Delta \mathbf{w}^{A}\right)\right) \mathbf{n}-g_{0}<0 \Rightarrow W=0(\text { passive node })
$$

$w(x, y)$ - the actual value of the gap between the plate and the foundation,

$\mathbf{n}$ - the unit normal vector to be assumed constant,

$W-$ the actual value of the normal contact force,

$\Delta \mathbf{w}$ - the value of an increment displacement due to load increment,

$g_{0}$ - the initial gap between the plate and the foundation.

The indices $A$ and $B$ correspond to the top and the bottom nodes of the zero-thickness interface element, respectively. In equation of constraint optimization (1) can be concisely written as the Kuhn-Tucker condition

$$
W w(x, y)=0, \quad W \leq 0, \quad w(x, y) \geq 0
$$

(ii) for the $(m+1)$ external load increment $\Delta \mathbf{R}_{m+1}$.

At the beginning of each load increment $(m+1)$, i.e. $\Delta \mathbf{R}_{m+1}$, the iteration scheme is based on the following parameters: the nodal displacements $\Delta \mathbf{w}_{m}$, the unbalanced forces $\boldsymbol{\Psi}_{m+1}^{n}$ and the nodal vector of internal forces $\Delta \mathbf{f}_{m+1}$. Thus within an increment of load $(m+1)$ we have

$$
\Delta \boldsymbol{\Psi}_{m+1}^{n}=\Delta \mathbf{R}_{m+1}-\left[\Delta \mathbf{f}_{m+1}^{n}+\Delta \mathbf{W}_{m+1}^{n}\right],
$$

where $m$ denotes the number of load increment, $n$ is the number of iteration at every increment, $\Delta \mathbf{f}_{m+1}$ is the nodal increment vector of internal forces, i.e., the resultant forces acting on each node from the surrounding elements which is calculated from the actual element stresses

$$
\Delta \mathbf{f}_{m+1^{n}}=\int \boldsymbol{B}^{T} \Delta \sigma_{m+1}^{n} d V
$$

while

$$
\Delta \mathbf{W}_{m+1}^{n}=k_{0} \iint_{A} \Delta \mathbf{w}_{m+1}^{n} \mathrm{~d} x \mathrm{~d} y .
$$

is the increment vector of the normal contact forces.

To define $\mathbf{w}_{m+1}^{n}$ in expression (3) we can use the Taylor series expansion up to first-order and write

$$
\Delta \boldsymbol{\Psi}^{n+1}=\Delta \boldsymbol{\Psi}^{n}+\frac{\partial\left(\Delta \boldsymbol{\Psi}^{n}\right)}{\partial\left(\mathbf{w}^{n}\right)} \Delta \mathbf{w}^{n} \cong \mathbf{0}
$$


For clarity we omit the superindex $(m+1)$ in the above expression. Substituting equations (3) and (4) to (6) lead to

$$
\Delta \boldsymbol{\Psi}_{m+1}^{n+1}=\left[\Delta \mathbf{R}_{m+1}-\left(\Delta \mathbf{f}_{m+1}^{n}+\Delta \mathbf{W}_{m+1}^{n}\right]-\left(\mathbf{K}_{T}\right)_{m+1}^{n} \Delta \mathbf{w}_{m+1}^{n}=\mathbf{0}\right.
$$

where the tangent stiffness matrix $\left(\mathbf{K}_{T}\right)_{m+1}^{n}$ is defined as

$$
\left(\mathbf{K}_{T}\right)_{m+1}^{n}=\frac{\partial\left(\Delta \boldsymbol{\Psi}^{n}\right)}{\partial\left(\Delta \mathbf{w}^{n}\right)}=\left[\left(\mathbf{K}_{e}^{e}\right)^{n}+\left(\mathbf{K}_{f}\right)^{n}\right]
$$

The first term in (8) represents the elastic stiffness matrix of the plate elements, while the second one corresponds to the stiffness matrix of the foundation. The term $\Delta \mathbf{w}_{m+1}^{n}$ from equation (7) can be used to find the accumulated displacement vector after $(n+1)$ iterations in the $(m+1)$ load increment acording to the following equation

$$
\Delta \mathbf{w}_{m+1}^{n+1}=\mathbf{w}_{m+1}^{n}+\Delta \mathbf{w}_{m+1}^{n} .
$$

At the end every iteration there should be a convergence check in order to see whether the iterative solution converged within the out-of-balance force tolerance (see equation (7)).

\section{Streszczenie}

W pracy zaprezentowano obliczenia za pomocą metody elementów skończonych płyty grubej spoczywającej na dwuparametrowym podłożu wielowarstwowym. Model numeryczny pozwala na dodanie dowolnej liczby warstw podłoża. Wyrażenia na obliczenie macierzy sztywności podłoża bazują na wykorzystaniu 18-węzłowego międzypowierzchniowego elementu kontaktowego o zerowej grubości. W celu zamodelowania elementu płyty grubej wykorzystano 9-węzłowy element płytowy z rodziny Lagrange'a zdefiniowany według teorii Mindlina. Sformułowanie uwzględnia zarówno wpływ naprężeń ścinających w płycie jak również warunki kontaktu jednostronnego pomiędzy płytą a podłożem. Warunki kontaktu jednostronnego są zrealizowane przez usunięcie odpowiedniej części macierzy sztywności podłoża, która przypisana jest do węzłów nie będących w kontacie. Poprawność zaproponowanego algorytmu zilustrowano kilkoma przykładmi numerycznymi.

Remarks on the paper should be

Received June 22, 2010 sent to the Editorial Office no later than December 30, 2010

revised version

September 15, 2010 